\title{
"Indefensible, Illogical, and Unsupported"; Countering Deficit Mythologies about the Potential of Students with Learning Disabilities in Mathematics
}

\author{
Rachel Lambert
}

Attallah College of Educational Studies, Chapman University, Orange, CA 92866, USA; lambertr@chapman.edu Received: 28 February 2018; Accepted: 12 April 2018; Published: 17 May 2018

\begin{abstract}
This paper describes two myths that circulate widely about the potential of students with Learning Disabilities to learn mathematics: (1) that students with Learning Disabilities cannot benefit from inquiry-based instruction in mathematics, and only from explicit instruction; and (2) that students with Learning Disabilities cannot construct their own mathematical strategies and do not benefit from engaging with multiple strategies. In this paper, I will describe how these myths have developed, and identify research that counters these myths. I argue that these myths are the unintended consequences of deficit constructions of students with Learning Disabilities in educational research. Using neurodiversity to frame disability as diversity rather than deficit, I assert that students with Learning Disabilities can learn mathematics to the highest levels, and that these limiting mythologies hold them back.
\end{abstract}

Keywords: mathematics education; disability studies; special education; equity; myths; neurodiversity

\section{Introduction}

The majority of students with disabilities [1] in the United States are being included in general education mathematics classrooms. This requires special educators and mathematics educators to collaborate in the design and implementation of mathematics curriculum that meets the Common Core State Standards for Mathematics [2]. These standards ask that students develop both conceptual and procedural knowledge, as well as engage in mathematical practices such as argumentation and problem-solving. Collaboration between special educators and math educators is complicated by different pedagogical recommendations from special education, which tends to recommend explicit instruction for students with disabilities, while mathematics education tends to recommend an inquiry approach to mathematical learning [3,4]. This creates uncertainty for collaborating professionals, who are forced to navigate seemingly contradictory recommendations about best practices [3].

The situation is further complicated by widely circulating deficit-based myths which limit the mathematical potential of students with disabilities. As a researcher on mathematics and disability, I frequently hear that students with Learning Disabilities (LD) cannot construct their own strategies when solving math problems, and that multiple strategies confuse them. I hear that direct instruction is the only effective pedagogy for students with LD, and that students with LD cannot benefit from inquiry-based mathematics instruction. I even hear that students with LD cannot learn concepts in mathematics. These myths circulate in staff rooms, professional development, and even in academic research. These myths are not relics of the past. In February of 2018, I read this tweet from a thoughtful math intervention teacher, seeking evidence to refute these myths: "Many times, I hear Ss with learning disabilities cannot think conceptually. Should just be given procedures. Is there research out there to refute this?" (Tweet quoted with permission). What exactly does it mean to say that a person, 
any person, "cannot think conceptually"? Where would such a statement come from? Consider the following quote published in a prominent special education journal in 1998:

"The premise that secondary students with LD will construct their own knowledge about important mathematical concepts, skills, and relationships, or that in the absence of specific instruction or prompting they will learn how or when to apply what they have learned, is indefensible, illogical, and unsupported by empirical investigations." ([5], p. 161).

Here, it is asserted that students with LD cannot construct their own knowledge in mathematics. Such a statement is itself indefensible, illogical and unsupported. To argue that any human is utterly incapable of thinking, of "constructing their own knowledge" is a shocking statement, rooted in a view of learners with LD that defines them by perceived deficits alone. Such ableism, or discrimination against those with disabilities, should not be tolerated in any field, but particularly in educational research.

When educators assume that students with LD are not capable of developing strategies, or of learning from inquiry-based methods, these students will be denied access to a well-rounded, rigorous mathematical curriculum such as outlined in the CCSS. Students with LD, as well as those who are labeled as low achieving in mathematics, are offered a more procedural mathematics when compared to their peers [6,7]. The documented positive outcomes of an inquiry approach to mathematics, not only in mathematical knowledge [8-11], but in developing student identities as agentic problem-solvers and a positive relationship towards mathematics [12,13], mean that we can no longer allow such beliefs to curtail the mathematical potential of students with LD.

When I consider the risks inherent in these myths, I think of the many students with LD that I have taught mathematics, such as Luis. Luis (A pseudonym) is Latino, with LD. When he was in middle school, he was a participant in a study of mine following students with LD through their sixth- and seventh-grade mathematics classrooms [14]. Luis adored conceptual work in mathematics, calling it "problems that give me problems," with a smile. He contrasted conceptual work with "worksheets, which are nothing." If his teacher gave a particularly interesting math problem and then moved on, more than once I saw him hide the problem under his textbook and work on it in secret. Indeed, Luis, and many other students like himself, relished and excelled at conceptual mathematics; it was procedural mathematics that challenged Luis.

In this paper, I will describe for how these myths have developed, as well as present empirical evidence that debunks them. I argue that these myths are the unintended consequences of pervasive deficit constructions of students with LD, and educators must move beyond these deficit conceptions to truly discover the mathematical potential of students with LD. I assert that students with LD can learn mathematics to the highest levels, and that these limiting mythologies hold them back.

\section{Rethinking Disability}

In this paper, I focus on Learning Disabilities (LD), the largest disability category in United States schools; $42 \%$ of all students in special education are categorized as LD [15]. I assert that ALL students with disabilities can make meaning in mathematics, with unlimited and often unrecognized potential as mathematicians. I focus on LD because it is the largest category, as well as because the majority of published research in mathematics focuses on LD. Specific Learning Disabilities is the umbrella term used in US law for students with dyslexia (LD in reading), dyscalculia or a Mathematical Learning Disability (LD in math or MLD), and dysgraphia (LD in writing), among other subgroups [15]. LD and MLD classification have long been contested fields [16,17], not only in the definitions of these disabilities, but in differentiating between those with $\mathrm{LD}$, and those who are having difficulty in school, but do not qualify for an LD label.

Multiple theoretical models can be used to frame disability. Disability in educational research is typically framed using a medical model, focusing on finding and remediating cognitive deficits [18]. Disability studies scholars and activists frame disability using the social model, which recognizes actual biological, neurological, or physical differences, but reserves the term disability for the disabling 
aspects of both society and an inaccessible built environment [18-20]. Those who use the social model do not argue that actual biological, neurological, and/or physical differences do not exist. On the contrary, those differences are significant parts of each individual's experience [19]. A shift to the social model of disability means a shift towards accessibility, rather than remediation alone.

Another model for disability is neurodiversity, a social justice movement that developed from the activism of people with autism, and includes dyslexia and other cognitive differences [21]. Neurodiverse individuals are demanding to be seen not as deficient, but as different: part of the natural and beneficial cognitive diversity of society. Several lines of inquiry in neuroscience have explored the varied cognitive strengths of dyslexic individuals [22]. Some of these strengths relate to mathematics, suggesting new visions of the potential of students with LD in mathematics. For example, one strength associated with dyslexia in several research studies is 3-D spatial thinking, connected to strengths in mechanics and complex visualization [23]. This skill has been associated with particular strength in mathematical tasks that involve manipulating 3-D space [24]. Another strength of some individuals with dyslexia is interconnected and narrative reasoning; individuals with dyslexia tend to make unique associations between concepts, and excel in discerning patterns [25].

Considering the cognitive strengths of those with LD [24], it seems illogical to frame these learners as incapable of conceptual thinking. For some, their strength is in the conceptual side of mathematics, suggesting that students with LD can achieve in mathematics to the highest levels. Consider this statement from a research mathematician who is dyslexic, "As a dyslexic, I've never been good at calculations or recalling rote facts like times tables. Here's the thing: beyond a certain point in mathematics, it's not really about calculations" [26]. He notes that geometry was when he found that a visual, spatial mathematics was a joyful endeavor: "Geometry class was when math became interesting, and easier for me. Suddenly I was in a world, not of strands of symbols to be processed, but of shape, space, lines, angles, concepts, and narrative-like proofs. Suddenly everything made sense" [26]. Dyslexic learners, then, can demonstrate particular gifts around spatial thinking and complex reasoning, yet consistently underperform in mathematics as it is currently taught in US schools [27]. One explanation is that mathematics education in the US has long been dominated by memorization, which disadvantages dyslexic learners, who have persistent difficulties memorizing disconnected information [28]. Such outcomes are possible not only for those with dyslexia, but dyscalculia as well; in this special issue, Lewis and Lane [29] describe how Lane, who has a mathematical learning disability, developed a unique set of strategies to succeed as a statistics major as an undergraduate.

\section{Debunking the Myths}

\subsection{Myth One: Students with LD Cannot Benefit from Inquiry Instruction in Mathematics}

Most often, I hear some variation on this myth, formulated multiple ways: students with LD cannot benefit from inquiry-based mathematics, or that students with LD must be taught using only explicit, direct instruction. This myth widely circulates, both in academic literature and in schools. I hear this myth from both special educators and mathematics educators.

This myth about students with disabilities has developed around the already existing parameters of larger debates about pedagogy in mathematics. When we compare research in mathematics education to research in special education that includes mathematics, we find two different research traditions who use different theoretical approaches to learning, as well as quite different methods [30]. Mathematics educational research has long been dominated by constructivist and sociocultural theories of learning, which tend to advocate for an inquiry-based pedagogy at both individual and collective levels [31]. Rather than breaking down topics into sub skills and teaching those directly, inquiry-based pedagogy first engages learners in problem-solving and discussion of complex problems, asking students to develop strategies without being explicitly taught them. Mathematics educational research has documented the effectiveness of inquiry approaches to learning mathematics [8-11], 
including for low achieving students [32,33]. Mathematics education has typically not included students with disabilities in research $[4,30]$.

Advocates for direct instruction have long been particularly influential in special education research, which developed from behaviorism and experimental psychology [34,35]. Recommended pedagogy within the academic fields of special education tends to be "explicit, systemic instruction", which "typically encompasses a step-by-step teacher demonstration for a specific type of problem along with teacher-guided and independent practice using the step-by-step procedure." ([36], p. 41). Special education mathematics has also been influenced by strategic instruction and, more recently, aspects of constructivism [4]. Yet historically, special education has long been suspicious of constructivist theories of learning [34]. Within the field, inquiry instruction was often framed as "discovery learning," and presented as if there is no teacher guidance, an inaccurate oversimplification of the approach. When Jones and colleagues [5] noted that allowing students with LD to construct their own ideas in mathematics is "illogical, indefensible, and unsupported by empirical investigation", they are making a pointed critique of constructivist mathematics, which they described as an "ideology".

There is a significant research base of quantitative studies that demonstrate the efficacy of explicit, direct instruction in teaching mathematics skills and procedures for students with Learning Disabilities [37]. The myth emerges from the assumption that there is sufficient evidence that inquiry mathematics is not effective for students with LD, or that explicit instruction is the only method that is evidence-based. As the National Mathematics Advisory Panel states, "it is important to note that there is no evidence supporting explicit instruction as the only mode of instruction for students [with LD]" ([38] p. 1229).

Another source for this myth is research in special education that has argued theoretically that students with LD cannot benefit from inquiry instruction because of their deficits. From one academic piece within special education: "To expect students who have a history of problems with automaticity, metacognitive strategies, memory, attention, generalization, proactive learning, and motivation to engage in efficient self-discovery learning ... is not plausible." ([39], p. 296). Some use the argument that the cognitive load of inquiry instruction will be problematic for students with LD because of working memory issues [40]. Others assume that students with MLD will be "confused" by inquiry-based mathematics because such instruction "places substantial demands on metacognitive skills, which may not be adequately developed in children with MLD" ([41], p. 52). This returns to the quote that opens the paper [5], in which the authors stated that it is illogical to assume that students with LD can construct their own knowledge in mathematics. These arguments frame LD with a medical model, which stresses the deficits associated with the disability. It is important to note that these quotes are taken from papers written between 1994 and 2004. I argue not that these exact statements would be made today, but that a legacy of these arguments is the pervasive myth that inquiry instruction cannot possibly work for students with LD.

However, there is evidence that students with LD can benefit from inquiry instruction in mathematics. In a series of rigorous mixed methods studies spanning over a decade, Bottge and colleagues have developed and assessed a curriculum specifically designed for students with LD to participate in inquiry mathematics, called Enhanced Anchored Instruction [42-45]. Drawing from both sociocultural theory, problem-solving in mathematics, and special education, this approach uses highly motivating, authentic contexts to scaffold the engagement of students with LD in inquiry-based mathematics. Through the use of video, researchers deeply immersed students with LD in contexts such as building skateboard ramps or hovercrafts to learn rational number concepts. By removing textual barriers, their work allows students to deeply engage in rich mathematical contexts. Their work has demonstrated the efficacy of inquiry-based mathematics instruction for students with LD in both resource rooms and inclusive general education classrooms. They found that some students with LD benefited from scaffolds such as computer representations of objects that could be rotated, additional instruction in underlying concepts such as fractions, and hands-on projects related to the context, such as building a ramp. 
Qualitative research that explores student thinking provides additional empirical evidence that students with LD can learn in inquiry classrooms. Moscardini found that students with learning disabilities were able to engage in open-ended problem solving, constructing their own strategies for story problems without prior instruction in procedures [46]. Chick and colleagues report on the learning of students with LD within a unit on fractions, using a reform-based curriculum [47]. Behrend has written about how a group of students with LD learned through engaging in open-ended problem-solving, again without prior instruction in procedures [48]. Foote and Lambert described a classroom in which third graders with IEPs were able to develop understandings of relational thinking and equivalency through engagement in a weekly open-ended problem-solving routine [49]. These studies provide evidence that students with LD can indeed learn challenging mathematics through inquiry-based mathematics. Similar findings have emerged in science, where inquiry-based curriculums have been effective for students with LD [50-52].

Increasingly, researchers in special education mathematics have integrated aspects of constructivism into their research [4]. For example, Hord and Newton, moving beyond a binary between explicit and inquiry, analyzed mathematics textbooks for both pedagogical features [53]. While recognizing the value in each pedagogy, they question if explicit instruction introduced too early can actually negatively impact conceptual understanding:

"In the short term, explicit instruction is potentially effective to help students solve problems more quickly; however, this earlier introduction of explicit instruction may slow the progress of students with LD in becoming resilient, persistent problem solvers and developing deep conceptual understanding of topics." ([53], p. 198).

They suggest that we need to consider the long-term time scale: inquiry mathematics allows students to take on agentic roles in relationship to mathematics and offers potential for long-term engagement with the subject [12]. When instructional decisions are focused on narrow time scales, rather than the long-term goals of developing agency and empowerment, we lose the forest for the trees. At risk are our students' identities as mathematical learners, which can suffer in a procedural curriculum [14].

My own research with Luis echoes these findings [14]. In the first half of his seventh-grade year, Luis's wonderful teacher, Ms. Marquez, engaged her students in inquiry-based mathematics. One day, she had her students working on the classic problem of buying hot dogs in packs of eight, and hot dog buns in packs of six. The class was discussing how many of each would need to be bought so that there were exactly enough buns for hot dogs, leading into the concept of Least Common Multiple. The discussion seemed over, and Ms. Marquez was about to move on when Luis raised his hand. She called on him with a smile, and he brought up the concept of infinity, asking how they could predict how the numbers would behave into infinity. The discussion started right back up again. When I asked Ms. Marquez who her top students were, she listed Luis right away, noting that he excelled at "conceptual" thinking.

However, later in his seventh-grade year, when classroom instruction was focused on procedural learning, Luis lost focus and interest. Ms. Marquez, Luis's seventh-grade-math teacher, faced considerable pressure to raise student test scores. In the second half of the school year, she focused heavily on direct instruction of procedures. While Ms. Marquez strongly disagreed with this shift away from inquiry-based instruction, she felt she must do so for the sake of the students, whose scores mattered in their high school applications. One day she taught the students a method for combining like coefficients, clearly outlining the steps. Luis raised his hand, curious about the $2 x$ written on the board. "But when," he asked, "WHEN will we multiply it?" His question suggested that he wondered how an expression, made of two parts that will somehow eventually multiply, would ever multiply. Faced with limited time before the test, his teacher moved on, providing more examples for the students to practice using the procedure. Luis put his head down on his desk, and did not engage in the rest of the lesson. In interviews, Ms. Marquez was deeply troubled by Luis's shift in engagement, and suggested that the shift in pedagogy was the culprit. 


\subsection{Myth Two: Students with LD Cannot Create Their Own Strategies and Should Not Be Taught Using Multiple Strategies}

I hear often that students with LD can't invent mathematical strategies, or deal with multiple mathematical strategies. Not only is this myth common in the US, but Peltenburg, Heuvel-Panhuizen, and Robitzsch [54] describe this as a commonly held belief in the Netherlands. There are two closely connected questions here: (1) should students with LD be directly taught strategies, or should they develop their own? and (2) should students with LD be taught one strategy or multiple strategies? Implicit in the assumption that students with LD need direct instruction of strategies is an assumption that students with LD cannot construct their own strategies. This myth is closely related to Myth 1 , and can be understood as a justification for that myth. In this argument, students with LD become overwhelmed with multiple strategies during inquiry instruction.

Recent studies have provided evidence dispelling this myth, demonstrating that students with disabilities and low achievers in mathematics can independently construct effective computational strategies. Peltenburg, Heuvel-Panhuizen, and Robitzsch [54] explored whether students in special education schools in the Netherlands would spontaneously use the adding-on strategy for subtraction, and if so, what elements of the task or problem mattered to elicit that strategy. They found that in general students in special education were able to invent the adding-on strategy successfully and use it effectively-more successfully, in fact, than removal. Students were more likely to do so if the problem had a context that suggested adding on, and if the numbers were close together and crossed a ten. Contrary to the commonly held myth, these special education students did not need to be directly taught a strategy in order to invent it. Students could move between strategies without difficulty, without prior direct instruction. Similarly, Peters, De Smedt, Torbeyns, Verschaffel, and Ghesquière [55] found that children with MLD were generally able to flexibly solve multi-digit subtraction problems, and like typically developing peers, these students switched between subtraction by removal and adding on. Other research has demonstrated that students with LD tend to develop the same strategies as typically developing peers, although the students with LD tended to use less sophisticated strategies longer than their peers [56].

In the area of fractions, Hunt and colleagues have demonstrated that students with LD can and do construct their own strategies to understand fractions [57-59]. These studies documented growth for students with LD when instruction was designed to closely understand student thinking in the area of fractions, and build tasks that develop those understandings. In short, we have strong evidence that students with LD can develop their own strategies for computation and problem solving, including sophisticated strategies.

Additional evidence debunking this myth comes from qualitative studies of students with LD in inquiry classrooms. Moscardini [46] notes that without prior instruction, the special education students in his study invented all the strategies outlined in previous general-education research studies [10]. Foote and Lambert [49] document that third-grade students in special education were able to independently construct strategies to solve relational thinking equations, when provided time and access to manipulatives. In the study by Chick and colleagues [47], two girls in special education constructed unique strategies for understanding fractions by using a clock as a model. Behrend [48] found that the two students in her study with LD were able to construct their own strategies when presented with open-ended mathematical tasks.

Another set of studies more specifically explored whether or not students with special education could benefit from instruction that included multiple strategies. Kroesbergen and van Luit [60] studied the effectiveness of Structured Instruction (SI) versus Guided Instruction (GI) in small-group interventions with both general education and special education, in multiplication. In the SI group, the teacher chose the strategy, modeled it, and students practiced. If students brought up a different strategy, the teacher led them back to the teacher's strategy. In the GI group, the teacher did not model any strategies after presenting the problems. Strategies emerged from the students, and the teacher led the discussion. Students then had a chance to practice the new strategies. Both small groups were 
given 4 months of instruction on solving multiplication problems. The study found that both groups were more effective than the control group (typical classroom instruction) in solving story problems in multiplication. Guided Instruction was slightly more effective for low-achieving students, but also proved effective for students in special education. This study suggests that assumptions that students with LD cannot learn from a multiple-strategies approach appear to be unfounded.

I know from years of experience teaching mathematics to students with learning disabilities that this myth is incorrect. My students with LD were able, just like other students, to develop their own strategies, given the opportunity. Each time he was given a problem, Luis sought to understand it, often drawing a picture or using a representation to find a way into the problem [14]. When learning how to add and subtract integers, for example, he modeled a number line and used the model to solve the problems. Ever the creative and critical thinker, he told me that he liked to think of the 0 in the number line as the border between Mexico and the US. Later in the school year, the teacher presented a rule for subtracting a negative number, by combining the signs into a positive sign. I watched for a few classes while Luis struggled to memorize this way of solving the problems. About a month later, Luis came up to me grinning, and told me in a whisper that the rule did not make sense to him, so now he just uses "the giant number line in my brain" to add and subtract integers. His own strategy stuck with him, when the strategies of others did not make sense to him.

As a reminder about the diversity within the category of LD, another student with LD in that same classroom, Desi, bemoaned being asked to create her own strategies, and wanted to be told what to do. She also told me that her previous teachers had always given her procedures. In contrast, Luis had been expected to develop strategies since kindergarten, as he went to an elementary school that used inquiry mathematics. I wonder then how much this difference between Desi and Luis, both students with LD, related to their prior experience learning mathematics? Moscardini [46] notes that while the younger students in his study were quick to use manipulatives to solve problems, older students were more hesitant to engage in independent problem-solving. He notes that these older students had spent significant time in classrooms in which they experienced only explicit instruction, and they were used to being told how to solve problems. This suggests another possible source for this myth: teachers who have experienced students who resist multiple strategies. When students who have only had experience with explicit, procedural mathematics are asked to develop their own strategies, they often initially hesitate. This is an issue for students with and without disabilities who have experienced primarily procedural mathematics. The issue here is not a deficit within the student, but learned habits that can be unlearned. As Hord and Newton [53] suggest, when students are provided with explicit instruction before they understand the concepts at play, these students may have difficulty engaging in those concepts through exploration.

\section{Discussion}

In this paper, I described a historical context for how these myths have developed. Broadly speaking, while many prominent researchers in mathematics education have advocated inquiry instruction, special education has continued to advocate for explicit instruction. Because much of special education has historically distrusted constructivist research, considering it to be discovery learning without any guidance [5,34], special educational researchers felt that inquiry instruction would not meet the needs of students with LD who tend to have more difficulty with working memory, metacognition, and executive functioning. While there is considerable evidence that students with LD can learn mathematics procedures through explicit instruction, that does not mean that they cannot learn through inquiry-based pedagogies. We have empirical evidence that students with LD can learn mathematics through inquiry curriculum, can invent their own strategies and learn through the strategies of others, and this may be particularly important for some of these learners, as indicated above. Returning to the language of the quote at the onset of this paper [5], these deficit myths about students with LD are unsupported by empirical investigations. 
These myths are predicated on the medical model of disability. When students with LD are understood primarily through their deficits, the solution from a medical model perspective is to remediate those deficits through targeted intervention. Students undergo treatments designed to fix them, in this case explicit interventions that will remediate the deficits. These deficit-focused arguments can be puzzling. Take for example the argument about memory, which suggests that students with LD cannot profit from inquiry-based instruction because of difficulties with memory. I agree that memory has often been an issue for many of the students with LD I have worked with over the years-sometimes a very pronounced issue. Using the medical model, we might assume that Luis has deficits in his memory which might have affected his ability to memorize the rules for adding and subtracting integers. But if his weakness is memorizing rules, why would we teach him through memorizing rules? Luis teaches us that he can use his strengths in visual processing to imagine a number line and use it to compute. Why would we not build on this, his unique strength? Focusing on deficits, rather than strengths, can be a counter-productive strategy. From this point of view, these myths are illogical, focused on remediating what challenges the learner, rather than building on their strengths. This will require a shift from a medical model, to neurodiversity, framing cognitive difference as diversity rather than deficit.

Finally, I assert that these myths are indefensible. Students with learning disabilities can learn mathematics to the highest levels, and these limiting mythologies hold them back. It is ableist to assume that a student with LD cannot think conceptually, or cannot benefit from an engaging and rigorous inquiry curriculum. Much more is at stake than the multiplication tables; mathematics instruction that is authentic, relevant, and engaging allows students to construct identities as mathematical thinkers [12,13] These identities are particularly important for students from groups that have been underserved in mathematics, such as African-American, Latino and Indigenous students [61], as well as women [61,62] and students with disabilities [14].

These myths have significant impact on students' lives, as the assumption that some students need a more explicit curriculum can result in tracking within schools and within classrooms. In Luis's classroom, half way through the year, his special education teacher created an "all-IEP group" to prepare students with LD for the state exams in mathematics. While other groups were allowed to work collaboratively, at whatever pace made sense, the "all-IEP group" moved at the pace of the teacher, who controlled discussion. This slower pace may have been helpful for some students, but Luis struggled mightily in this small group. His special educator, a thoughtful and kind educator, told me later that Luis "needed" this kind of "support". For Luis, being placed in a small group with other students with IEPs did not seem like the right kind of support. But such a move makes sense if one believes that he needs a more explicit curriculum since he has LD. This is echoed across classrooms, schools and countries; students with LD, as well as those who are labeled as low achieving in mathematics, are offered a more procedural mathematics when compared to their peers [6,7]. To disrupt these patterns of unequal access to meaningful mathematics, we need to disrupt these mythologies, and reimagine our understanding of the mathematical potential of students with LD.

\section{Implications}

I have three recommendations for practitioners and researchers. First, we need to understand disability as a part of equity, and support social justice for students with disabilities. For too long, disability has stood apart from other identity categories. Students with LD were seen not as a having a particular social identity, but a medical condition. This is shifting, with movements such as the Disability Rights Movement and neurodiversity, which reframe disability as difference, rather than deficit. Access to meaningful curriculum in mathematics is then an equity issue, not simply an issue of effectiveness, measured in the short-term. Researchers and teachers need to privilege the perspectives of those with disabilities. They are the real experts on disability and learning.

Second, engage all students in standards-based, inquiry-based instruction, but provide structures and supports so that all students will be successful. Much of the research on students with LD 
in inquiry mathematics describes scaffolds that supported student learning without diminishing the cognitive demand of the tasks [11]. For example, the students in Moscardini's study [46] were supported in engaging in demanding problem solving when teachers reread the story problem to them, making sure that they understood the problem. Students with LD can be supported to engage in inquiry curriculum through multi-modal curriculum, teacher questioning, and supports for collaboration in small groups [63]. Research should support teachers in this work by learning more about effective scaffolds, which are likely to be helpful for all learners.

Finally, I recommend that we address these myths by supporting collaboration and knowledge sharing between special education and mathematics education. Moving beyond these myths will require sustained collaboration between special educators and mathematics education at multiple levels. The differences between special education research and mathematics educational research are much more complex and nuanced than my brief introduction allows (for a detailed analysis, see $[4,30,34])$. In schools, the issues become even more complex. In Luis's sixth grade year, his mathematics teacher tended to teach procedurally, while the special education coteacher introduced inquiry methods into the classroom, and regularly ran discussions with the whole class focused on student thinking [14]. In Luis's seventh grade year, his math teacher began the year with an inquiry-based curriculum, and then shifted to an explicit, procedural curriculum to prepare students for the test. The special educator entered the classroom during this time, and taught a small group of students with LD using a more explicit approach. Special educators, then, do not all advocate for explicit instruction, nor do all mathematics teachers enact an inquiry-based curriculum. All teachers are also impacted by institutional demands, such as mandated curriculum and standardized tests.

At the classroom level, I recommend coteaching as a practice in which mathematics educators and special educations plan, teach, and debrief together [64]. Effective coteaching will require sustained professional development in which both teachers develop understanding of mathematical development, curricular design and both the challenges and strengths of students with disabilities. It also requires that the teachers have adequate time to plan curriculum together. Teacher education programs also need to foster collaboration between special education and mathematics education. In turn, research on the mathematical learning of students with disabilities must integrate neurodiversity into research design and implementation. By designing instruction that builds on both student knowledge and teachers' knowledge of their students, special educators and mathematics educators can together move beyond these myths to radically redesign mathematics classrooms for students like Luis.

Acknowledgments: No funding for this work. I would like to thank Tracy Zager and Casey Hord for their helpful comments.

Conflicts of Interest: The author declares no conflict of interest.

\section{References}

1. US Department of Education. 38th Annual Report to Congress on the Implementation of the Individuals with Disabilities Education Act; US Department of Education: Washington, DC, USA, 2016.

2. National Governors Association Center for Best Practices \& Council of Chief State School Officers. Common Core State Standards for Mathematics; National Governors Association Center for Best Practices \& Council of Chief State School Officers: Washington, DC, USA, 2010.

3. Boyd, B.; Bargerhuff, M.E. Mathematics education and special education: Searching for common ground and the implications for teacher education. Math. Teach. Educ. Dev. 2009, 11, 54-67.

4. van Garderen, D.; Scheuermann, A.; Jackson, C.; Hampton, D. Supporting the collaboration of special educators and general educators to teach students who struggle with mathematics: An overview of the research. Psychol. Sch. 2009, 46, 56-78. [CrossRef]

5. Jones, E.D.; Wilson, R.; Bhojwani, S. Mathematics instruction for secondary students with learning disabilities. J. Learn. Disabil. 1997, 30, 151-163. [CrossRef] [PubMed]

6. Weiss, I.R.; Pasley, J.D.; Smith, P.S.; Banilower, E.R.; Heck, D.J. Looking Inside the Classroom: A Study of K-12 Mathematics and Science Education in the United States; Horizon Research Inc.: Chapel Hill, NC, USA, 2003. 
7. Jackson, H.G.; Neel, R.S. Observing mathematics: Do students with EBD have access to standards-based mathematics instruction? Educ. Treat. Child. 2006, 29, 593.

8. Boaler, J. Experiencing School Mathematics: Traditional and Reform Approaches to Teaching and Their Impact on Student Learning; Lawrence Erlbaum: Mahwah, NJ, USA, 1997.

9. Boaler, J.; Staples, M. Creating mathematical futures through an equitable teaching approach: The case of Railside School. Teach. Coll. Rec. 2008, 110, 608-645.

10. Carpenter, T.P.; Fennema, E.; Franke, M.L.; Levi, L.; Empson, S.B. Cognitively Guided Instruction: A ResearchBased Teacher Professional Development Program for Elementary School Mathematics; Research Report; ERIC: 2000. Available online: https:/ / files.eric.ed.gov / fulltext/ED470472.pdf (accessed on 12 January 2018).

11. Silver, E.A.; Stein, M.K. The Quasar Project: The "revolution of the possible" in mathematics instructional reform in urban middle schools. Urban Educ. 1996, 30, 476-521. [CrossRef]

12. Boaler, J.; Selling, S.K. Psychological Imprisonment or Intellectual Freedom? A Longitudinal Study of Contrasting School Mathematics Approaches and Their Impact on Adults' Lives. J. Res. Math. Educ. 2017, 48, 78-105. [CrossRef]

13. Horn, I.S. Turnaround students in high school mathematics: Constructing identities of competence through mathematical worlds. Math. Think. Learn. 2008, 10, 201239. [CrossRef]

14. Lambert, R. Constructing and resisting disability in mathematics classrooms: a case study exploring the impact of different pedagogies. Educ. Stud. Math. 2015, 89, 1-18. [CrossRef]

15. Cortiella, C.; Horowitz, S.H. The State of Learning Disabilities: Facts, Trends and Emerging Issues; National Center for Learning Disabilities: New York, NY, USA, 2014.

16. McFarland, L.; Williams, J.; Miciak, J. Ten years of research: A systematic review of three refereed LD journals. Learn. Disabil. Res. Pract. 2013, 28, 60-69. [CrossRef]

17. Lewis, K.E.; Fisher, M.B. Taking stock of 40 years of research on mathematical learning disability: Methodological issues and future directions. J. Res. Math. Educ. 2016, 47, 338-371. [CrossRef]

18. Linton, S. Claiming Disability: Knowledge and Identity; NYU Press: New York, NY, USA, 1998.

19. Siebers, T. Disability Theory; University of Michigan Press: Ann Arbor, MI, USA, 2008.

20. Tan, P.; Kastberg, S. Calling for Research Collaborations and the Use of Dis/ability Studies in Mathematics Education. J. Urban Math. Educ. 2017, 10, 25-38.

21. Robertson, S.M.; Ne'eman, A.D. Autistic acceptance, the college campus, and technology: Growth of neurodiversity in society and academia. Disabil. Stud. Q. 2008, 28, Available online: http://dsq-sds.org/ article/view/146/146 (accessed on 17 May 2018). [CrossRef]

22. Trott, C. The Neurodiverse Mathematics Student; The University of Birmingham with The Higher Education Academy: Birmingham, UK, 2015.

23. Attree, E.A.; Turner, M.J.; Cowell, N. A virtual reality test identifies the visuospatial strengths of adolescents with dyslexia. Cyber Psychol. Behav. 2009, 12, 163-168. [CrossRef] [PubMed]

24. Eide, B.; Eide, F. The Dyslexic Advantage: Unlocking the Hidden Potential of the Dyslexic Brain; Reprint edition; Plume: New York, NY, USA, 2012.

25. Everatt, J.; Weeks, S.; Brooks, P. Profiles of strengths and weaknesses in dyslexia and other learning difficulties. Dyslexia 2008, 14, 16-41. [CrossRef] [PubMed]

26. Math and Science with My Kids. Available online: https://toomai.wordpress.com/2014/09/17/dyslexicmathematician/ (accessed on 1 September 2017).

27. Wei, X.; Lenz, K.B.; Blackorby, J. Math growth trajectories of students with disabilities: Disability category, gender, racial, and socioeconomic status differences from ages 7 to 17. Remedial Spec. Educ. 2013, 34, 154-165. [CrossRef]

28. De Weerdt, F.; Desoete, A.; Roeyers, H. Working Memory in Children with Reading Disabilities and/or Mathematical Disabilities. J. Learn. Disabil. 2012, 46, 461-472. [CrossRef] [PubMed]

29. Lewis, K.E.; Lynn, D.L. Against the Odds: Insights from a Statistician with Dyscalculia. Educ. Sci. 2018, 8, 63. [CrossRef]

30. Lambert, R.; Tan, P. Conceptualizations of students with and without disabilities as mathematical problem solvers in educational research: A critical review. Educ. Sci. 2017, 7, 51. [CrossRef]

31. Lerman, S. The social turn in mathematics education research. In Multiple Perspectives on Mathematics Teaching and Learning; Greenwood Publishing Group: California, CA, USA, 2000; pp. 19-44. 
32. Burris, C.C.; Heubert, J.P.; Levin, H.M. Accelerating mathematics achievement using heterogeneous grouping. Am. Educ. Res. J. 2006, 43, 137-154. [CrossRef]

33. Burris, C.C.; Wiley, E.; Welner, K.; Murphy, J. Accountability, rigor, and detracking: Achievement effects of embracing a challenging curriculum as a universal good for all students. Teach. Coll. Rec. 2008, 110, 571-607.

34. Woodward, J. Mathematics education in the United States: Past to present. J. Learn. Disabil. 2004, 37, 16-31. [CrossRef] [PubMed]

35. Osgood, R.L. The History of Special Education: A Struggle for Equality in American Public Schools; Greenwood Publishing Group: New York, NY, USA, 2008.

36. Powell, S.R.; Fuchs, L.S.; Fuchs, D. Reaching the mountaintop: Addressing the common core standards in mathematics for students with mathematics difficulties. Learn. Disabil. Res. Pract. 2013, 28, 38-48. [CrossRef]

37. Kroesbergen, E.H.; Van Luit, J.E. Mathematics interventions for children with special educational needs: A meta-analysis. Remedial Spec. Educ. 2003, 24, 97-114. [CrossRef]

38. Gersten, R.; Beckmann, S.; Clarke, B.; Foegen, A.; Marsh, L.; Star, J.R.; Witzel, B. Assisting Students Struggling with Mathematics: Response to Intervention (RtI) for Elementary and Middle Schools. NCEE 2009-4060. What Works Clearinghouse. Available online: https:/ /ies.ed.gov/ncee/wwc/practiceguide/2 (accessed on 17 May 2018).

39. Mercer, C.D.; Jordan, L. Implications of constructivism for teaching math to students with moderate to mild disabilities. J. Spec. Educ. 1994, 28, 290. [CrossRef]

40. Baxter, J.A.; Woodward, J.; Olson, D. Effects of reform-based mathematics instruction on low achievers in five third-grade classrooms. Elem. Sch. J. 2001, 101, 529-547. [CrossRef]

41. Desoete, A.; Roeyers, H.; de Clercq, A. Children with Mathematics Learning Disabilities in Belgium. J. Learn. Disabil. 2004, 37, 50-61. [CrossRef] [PubMed]

42. Bottge, B.A.; Heinrichs, M.; Chan, S.; Serlin, R.C. Anchoring adolescents' understanding of math concepts in rich problem-solving environments. Remedial Spec. Educ. 2001, 22, 299. [CrossRef]

43. Bottge, B.A.; Rueda, E.; Serlin, R.C.; Hung, Y.-H.; Kwon, J.M. Shrinking achievement differences with anchored math problems: Challenges and possibilities. J. Spec. Educ. 2007, 41, 31-49. [CrossRef]

44. Bottge, B.A.; Stephens, A.C.; Rueda, E.; LaRoque, P.T.; Grant, T.S. Anchoring Problem-Solving and Computation Instruction in Context-Rich Learning Environments. Except. Child. 2010, 76, 417-437. [CrossRef]

45. Bottge, B.A.; Toland, M.D.; Gassaway, L.; Butler, M.; Choo, S.; Griffen, A.K.; Ma, X. Impact of enhanced anchored instruction in inclusive math classrooms. Except. Child. 2015, 158. [CrossRef]

46. Moscardini, L. 'I like it instead of maths': How pupils with moderate learning difficulties in Scottish primary special schools intuitively solved mathematical word problems. Br. J. Spec. Educ. 2010, 37, 130-138. [CrossRef]

47. Chick, C.; Tierney, C.; Storeygard, J. Seeing Students' Knowledge of Fractions: Candace's Inclusive Classroom. Teach. Child. Math. 2007, 14, 52-57.

48. Behrend, J.L. Learning-disabled students make sense of mathematics. Teach. Child. Math. 2003, 9, $269-273$.

49. Foote, M.Q.; Lambert, R. I have a solution to share: Learning through equitable participation in a mathematics classroom. Can. J. Sci. Math. Technol. Educ. 2011, 11, 247-260. [CrossRef]

50. Scruggs, T.E.; Mastropieri, M.A.; Bakken, J.P.; Brigham, F.J. Reading versus Doing: The Relative Effects of Textbook-Based and Inquiry-Oriented Approaches to Science Learning in Special Education Classrooms. J. Spec. Educ. 1993, 27, 1-15. [CrossRef]

51. Mastropieri, M.A.; Scruggs, T.E.; Norland, J.J.; Berkeley, S.; McDuffie, K.; Tornquist, E.H.; Connors, N. Differentiated curriculum enhancement in inclusive middle school science: Effects on classroom and high-stakes tests. J. Spec. Educ. 2006, 40, 130-137. [CrossRef]

52. Palincsar, A.S.; Magnusson, S.J.; Collins, K.M.; Cutter, J. Making Science Accessible to All: Results of a Design Experiment in Inclusive Classrooms. Learn. Disabil. Q. 2001, 24, 15-32. [CrossRef]

53. Hord, C.; Newton, J.A. Investigating Elementary Mathematics Curricula: Focus on Students with Learning Disabilities. Sch. Sci. Math. 2014, 114, 191-201. [CrossRef]

54. Peltenburg, M.; van den Heuvel-Panhuizen, M.; Robitzsch, A. Special education students' use of indirect addition in solving subtraction problems up to 100-A proof of the didactical potential of an ignored procedure. Educ. Stud. Math. 2012, 79, 351-369. [CrossRef]

55. Peters, G.; De Smedt, B.; Torbeyns, J.; Verschaffel, L.; Ghesquière, P. Subtraction by addition in children with mathematical learning disabilities. Learn. Instr. 2014, 30, 1-8. [CrossRef] 
56. Jordan, N.C.; Hanich, L.B.; Kaplan, D. A longitudinal study of mathematical competencies in children with specific mathematics difficulties versus children with comorbid mathematics and reading difficulties. Child Dev. 2003, 74, 834-850. [CrossRef] [PubMed]

57. Hunt, J.; Empson, S. Exploratory study of informal strategies for equal sharing problems of students with learning disabilities. Learn. Disabil. Q. 2014, 38. [CrossRef]

58. Hunt, J.H. Notions of equivalence through ratios: Students with and without learning disabilities. J. Math. Behav. 2015, 37, 94-105. [CrossRef]

59. Hunt, J.; Tzur, R. Where is Difference? Processes of Mathematical Remediation through a Constructivist Lens. J. Math. Behav. 2017, 48, 62-76. [CrossRef]

60. Kroesbergen, E.H.; Luit, J.E.H. van Teaching multiplication to low math performers: Guided versus structured instruction. Instr. Sci. 2002, 30, 361-378. [CrossRef]

61. Zavala, M.d.R. Latina/o Youth's Perspectives on Race, Language, and Learning Mathematics. J. Urban Math. Educ. 2014, 7, 55-87.

62. Solomon, Y. Finding a voice? Narrating the female self in mathematics. Educ. Stud. Math. 2012, 80, 171-183. [CrossRef]

63. Lambert, R. 'When I am being rushed it slows down my brain': Constructing self-understandings as a mathematics learner. Int. J. Incl. Educ. 2017, 21, 521-531. [CrossRef]

64. Danforth, S. (Ed.) Becoming a Great Inclusive Educator, 1st ed.; Peter Lang Publishing Inc.: New York, NY, USA, 2014.

(C) 2018 by the author. Licensee MDPI, Basel, Switzerland. This article is an open access article distributed under the terms and conditions of the Creative Commons Attribution (CC BY) license (http:/ / creativecommons.org/licenses/by/4.0/). 